\title{
Modelo de recuperación de créditos castigados y la generación de utilidades en el sistema bancario peruano 2017 al 2020
}

\section{Model for the recovery of written off loans and the generation of profits in the Peruvian banking system 2017 to 2020}

Manuel Alberto Munsibay-Muñoa

Universidad César Vallejo, Trujillo, Perú

mmunsibay@gmail.com

(D) https://orcid.org/0000-0001-9927-5909

Lauralinda Leonor Caver-Egúsquiza-Vargas

Universidad César Vallejo, Trujillo, Perú

lauralinda.cavero@gmail.com

(iD https://orcid.org/0000-0001-5222-8865

José De La Rosa Orderique-Torres

Universidad César Vallejo, Trujillo, Perú

jorderiquet@ucv.edu.pe

(D) https://orcid.org/0000-0002-9719-8708

Jenny Yessica Zárate-Gavidia

Universidad César Vallejo, Trujillo, Perú

yzg_15@hotmail.com

(iD https://orcid.org/0000-0002-3626-4820

Recepción: 02/08/2021 | Aceptación: 09/11/2021 | Publicación: 25/11/2021

Cómo citar (APA, séptima edición):

Munsibay-Muñoa, M.A., Cavero-Egúsquiza-Vargas, L.L., Orderique-Torres, J. R., Zárate-

Gavidia, J.Y. (2021). Modelo de recuperación de créditos castigados y la generación de utilidades en el sistema bancario peruano 2017 al 2020. INNOVA Research Journal, 6(3.2), 118-

140. pp. https://doi.org/10.33890/innova.v6.n3.2.2021.1872

\section{Resumen}

El presente artículo cuyo título es modelo de recuperación de créditos castigados y la generación de utilidades en el sistema bancario peruano 2017 al 2020 surgió por el interés de identificar 
medidas para reducir el riesgo de las instituciones financieras y especialmente los bancos. El objetivo de la investigación es implementar un modelo de recuperación de créditos castigados, los cuales son difíciles de cobrar. La metodología empleada fue de tipo aplicativo, enfoque cuantitativo, diseño no experimental y descriptivo, la técnica utilizada fue el análisis documental y el instrumento fue la ficha técnica de sistematización. Los resultados obtenidos después de aplicar el modelo, se determinó un VANE incremental de \$2.69 millones de dólares y una TIRE de $121 \%$, con estos resultados se acepta el modelo propuesto y de acuerdo al análisis de sensibilidad se deduce que el incremento de la recuperación de la cartera castigada luego de la aplicación del modelo debe ser superior a $17.25 \%$, obteniendo una TIR del $121.00 \%$. Se concluye que las utilidades del sistema bancario en el 2020 han sido positivas, la banca múltiple obtuvo 2,111.57 millones de soles, con respecto al año 2019 que obtuvo una cifra récord de 9,082.31 millones de soles, para los años 2018 al 2020 la cartera refinanciada ha tenido un incremento de $22 \%, 2 \%$ y $36 \%$ con respecto al año anterior respectivamente y la cartera atrasada (vencida más la judicializada) ha tenido un incremento de $7 \%, 8 \%$ y $43 \%$ con respecto al año anterior respectivamente.

Palabras claves: sistema bancario peruano; tasas de interés; cartera crediticia; colocaciones; utilidades.

\begin{abstract}
This article, whose title is a model for the recovery of written-off loans and the generation of profits in the Peruvian banking system from 2017 to 2020, arose out of the interest of identifying measures to reduce the risk of financial institutions and especially banks. The objective of the research is to implement a model for the recovery of bad debts, which are difficult to collect. The methodology used was of an applicative type, quantitative approach, non-experimental and descriptive design, the technique used was the documentary analysis and the instrument was the systematization technical sheet. The results obtained after applying the model, an incremental NPV of \$ 2.69 million dollars and an EIRR of 121\% were determined, with these results the proposed model is accepted and according to the sensitivity analysis it is deduced that the increase in the recovery of the portfolio written off after the application of the model must be higher than $17.25 \%$, obtaining an Internal Rate of Return of $121.00 \%$. It is concluded that the profits of the banking system in 2020 have been positive, multiple banking obtained 2,111.57 million soles, compared to 2019 that obtained a record figure of 9,082.31 million soles, for the years 2018, 2019 and 2020 the portfolio refinanced has had an increase of $22 \%, 2 \%$ and $36 \%$ with respect to the previous year respectively and the delinquent portfolio (past due plus the judicialized one) has had an increase of 7\%,8\% and $43 \%$ with respect to the previous year respectively.
\end{abstract}

Keywords: peruvian banking system; interest rates; loan portfolio; loans; profits.

\title{
Introducción
}

La economía peruana tuvo un crecimiento significativo en los últimos años sustentándose en las exportaciones y los precios internacionales de los commodities, especialmente por el incremento de los productos no tradicionales desde el año 2007 al 2019. Para el año 2020, afectado por la pandemia, el Producto Bruto Interno (PBI) tuvo un decrecimiento del $-11 \%$ después de crecer $2.5 \%$ (2017), 4\% (2018) y 2.2\% (2019), este artículo tiene como objetivo implementar un modelo de recuperación de créditos castigados, los cuales son difíciles de cobrar y que sirva a los bancos del sistema financiero peruano para reducir el riesgo postpandemia. 
La mayoría de los sectores económicos fueron afectados por el COVID-19, trabajando al $40 \%$ de su capacidad. En la figura 1 se observa el comportamiento del Producto bruto interno y la demanda interna en variaciones porcentuales.

\section{Figura 1}

Producto Bruto Interno y la demanda interna (Variaciones porcentuales reales)

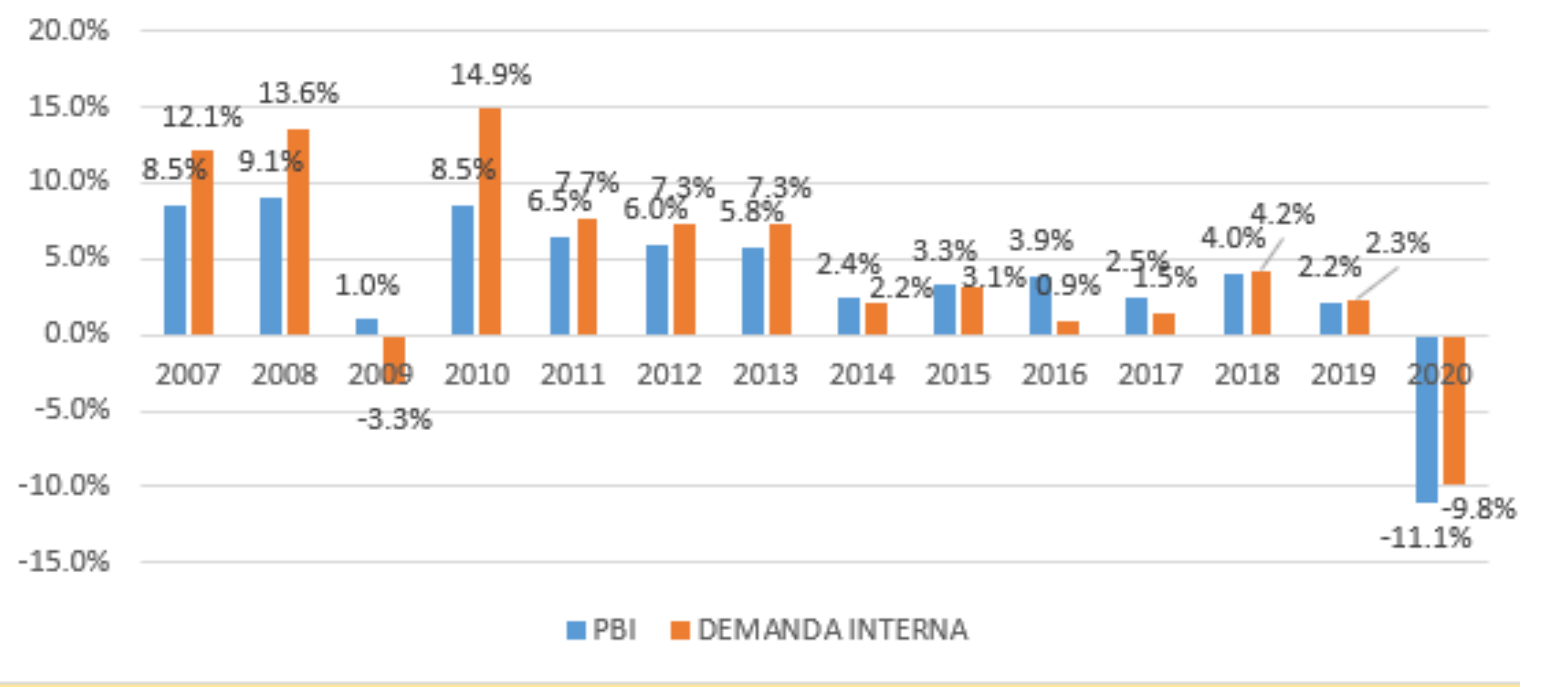

Fuente: Banco central de reserva - estadísticas cuadros anuales históricos.

Después de este escenario negativo que se muestra en la figura 1, la actividad económica tuvo una recuperación gradual debido a la implementación de las medidas de estímulo monetario y fiscal originando el reinicio de los proyectos de inversión y un rescate de la demanda externa.

Por otro lado, el aspecto fiscal, durante los últimos cuatro años, ha sido orientada a incrementar la demanda interna y contrarrestar las tendencias recesivas teniendo claro el principio de sostenibilidad fiscal, contribuir al fortalecimiento de las finanzas públicas, mejorar las condiciones de las finanzas internacionales en la economía peruana y resguardar el soporte a la estabilidad macroeconómica del país y credibilidad de la política fiscal, reflejando en ello un crecimiento económico sostenido aún en un contexto de turbulencia internacional que han afectado a todas las economías de la región. La proyección del déficit fiscal se ha reducido de 9.2 a 8.6 por ciento del PBI para el 2020 y para el 2021 se espera una reducción de 5.1 a 4.4 porciento esto se debe a una mayor recaudación de ingresos corrientes, los cuales se ubicarían en $18.8 \%$ para el 2021 y 19.7 por ciento en el 2022. El gobierno central continúa con la política fiscal planteada con el objetivo de enfrentar los problemas presentados por el COVID-19 continuando con el proceso de consolidación hasta el año 2022 que se debe registrar un déficit de 3\% del PBI. El impulso fiscal tiene como base el resultado económico que es producto de las variaciones del gasto público y las políticas tributarias. El impulso fiscal ponderado es un indicador alternativo que mide los cambios en los ingresos estructurales, los gastos corrientes y de capital mostrando una política expansiva para el 2020 estimándose un 1,5 por ciento del PBI tendencial (Banco central de reserva del Perú, 2020). 
Se debe tomar en consideración la política monetaria expansiva aplicada por el Banco Central de Reserva del Perú dejando la tasa interés de referencia en $0.25 \%$ para mejorar las perspectivas económicas en los siguientes años, estimulando la economía, continuar con el dinamismo y generando liquidez en el sistema financiero, ver figura 2.

\section{Figura 2}

\section{Tasa de referencia}

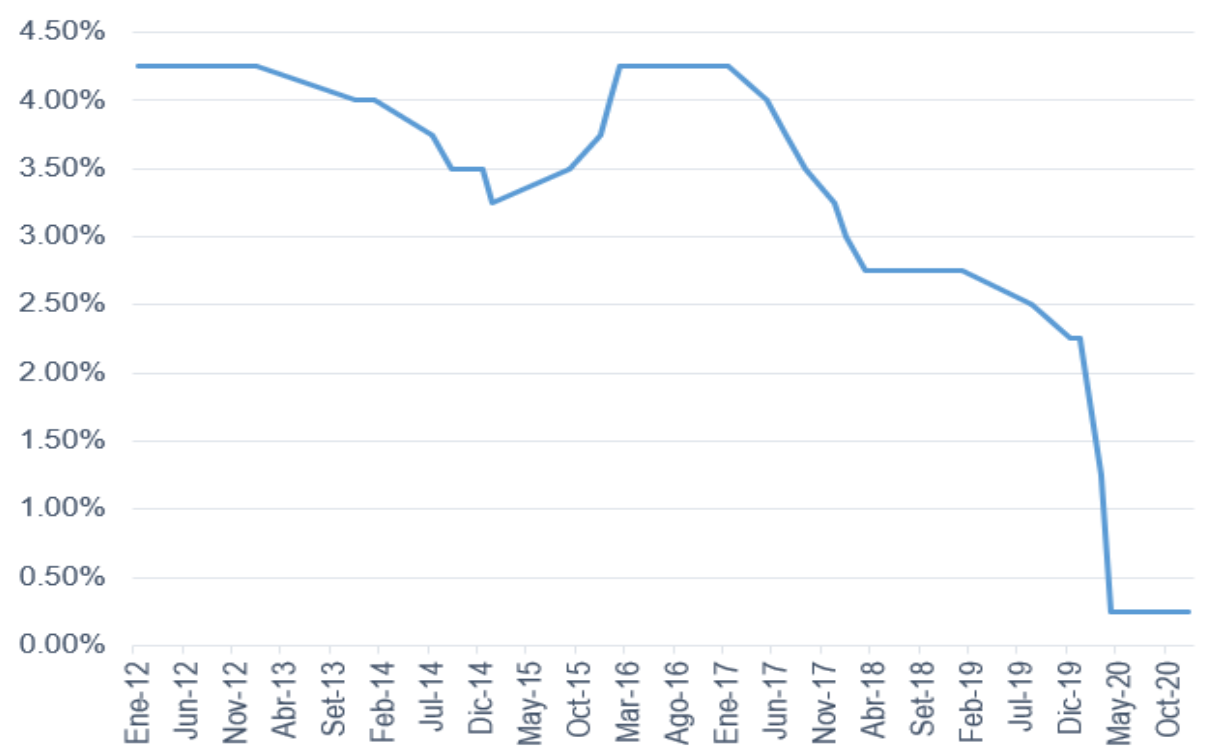

Fuente: Nota informativa BCRP

El sistema bancario peruano tuvo utilidades pese a la reducción de 77\% de sus beneficios respecto al año anterior. En el Perú el sistema financiero está regulado por la ley $\mathrm{N}^{\circ} 26702$ de la Superintendencia de banca y seguros (SBS y AFP), quien supervisa y regula todas las entidades del sistema financiero y de seguros. Se toma en cuenta a las empresas e instituciones que captan fondos del público y lo colocan en forma de créditos e inversiones En el 2020 las colocaciones de la banca múltiple se incrementó en un 13\%, esto se debió al apoyo de garantías del gobierno central a través de Reactiva Perú, creado por Decreto Legislativo 1455 y que fueron colocados a través de las empresas del sistema financiero (Banca Múltiple). Del mismo modo, la cartera atrasada de la Banca Múltiple tuvo un incremento de un 43\%. El impacto del COVID-19 en el mercado financiero peruano ha sido moderado por ser estable y contar con una buena liquidez, también apoyados por las medidas adoptadas por el gobierno para reducir los riesgos macrofinancieros ocasionados por la pandemia, este estímulo monetario ha impulsado el crédito a las empresas, conteniendo el aumento de la morosidad en el sistema y las reprogramaciones de créditos de consumo por parte de los bancos con mayor tamaño, permitieron proteger la estabilidad del sistema financiero. Pero la incertidumbre en los mercados financieros internacionales podría ocasionar en el corto plazo mayor volatilidad al sistema financiero peruano. En los últimos años el sistema bancario nacional continúa fortaleciendo, reflejando en ello la recuperación de la rentabilidad, calidad de la cartera de créditos y amplios saldos de liquidez, tal es así que el incremento de las 
colocaciones ha oscilado para el 2017 en un 3\% y un 13\% para el 2020. (Banco Central de reserva del Perú, 2020)

En la figura 3 se observa las colocaciones y depósitos de la banca múltiple en millones de soles, donde se refleja el comportamiento desde 2007 al 2020 mostrando una tendencia creciente siendo mayor los depósitos en los años 2007 (s/ 70,547 millones), 2008 (s/93,469 millones), 2009 (s/. 95,518 millones), 2010 (s/ 115,446 millones), 2011 (s/ 126,435 millones), 2013 (s/ 170,933 millones) y finalmente el 2020 subió a s/ 327,047 millones por las medidas del gobierno que permitieron la liquidez en los hogares a través del retiro de AFP del 25\% y el otorgamiento de los bonos universales (Superintendencia de banca y seguros, 2020).

\section{Figura 3}

Colocaciones y depósitos de la banca múltiple (millones de soles)

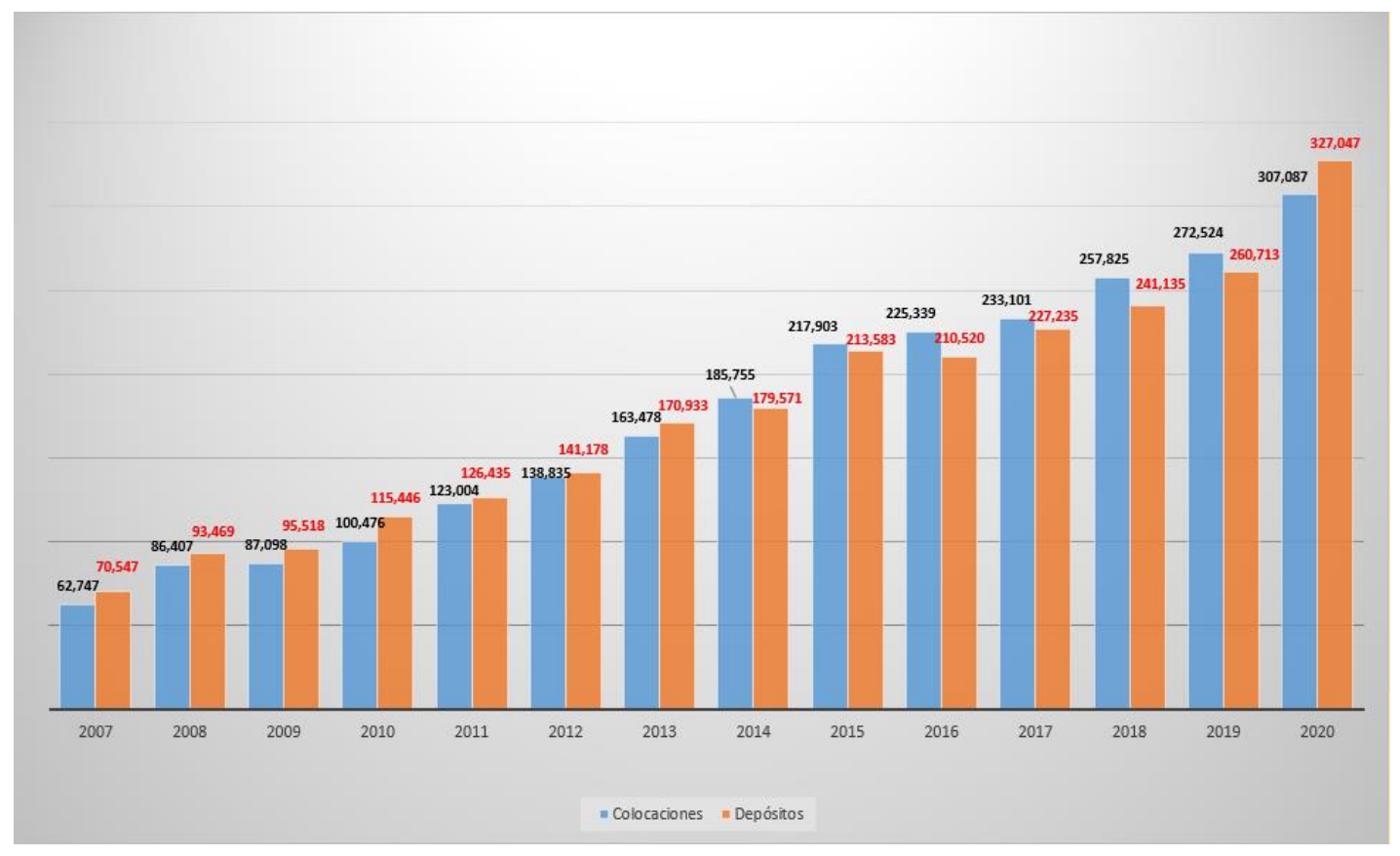

Fuente: Datos históricos SBS

En la figura 4 se puede observar el incremento de la cartera atrasada llegando a $4.03 \%$ en el año 2020, siendo la cartera refinanciada y estructurada en $1.83 \%$, muchas de las entidades financieras han reprogramado de manera automática los créditos evitando así el rompimiento de la cadena de pagos en la economía, aliviando el flujo de caja de las personas afectadas por la crisis sanitaria que no pueden hacer frente a sus obligaciones crediticias. El banco central de reserva impulsando la reprogramación de los créditos a tasas menores y plazos mayores emite la circular $\mathrm{N}^{\circ}$ 0021-2020-BCRP (05 de junio 2020), donde se indica que las empresas del sistema financiero vendan temporalmente al BCRP títulos valores conteniendo la cartera de créditos o moneda extranjera obligándose a recomprarlos al vencimiento (Superintendencia de banca y seguros, 2020). 


\section{Figura 4}

Cartera atrasada-refinanciación y reestructura (Porcentual con respeto a las colocaciones netas)

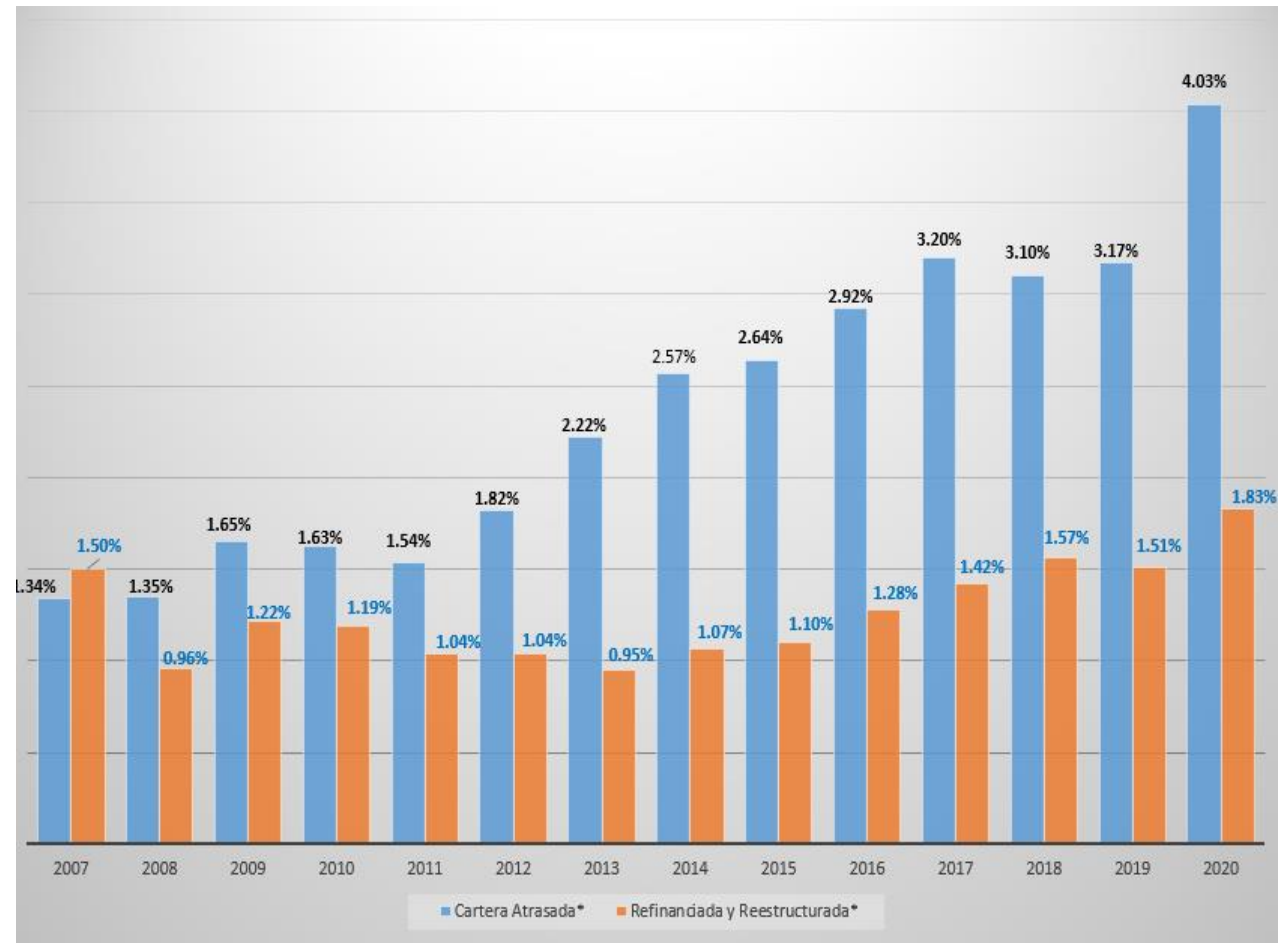

Fuente: Datos históricos SBS

En la tabla 1 se observa las utilidades de los principales bancos del sistema financiero peruano en millones de soles, el banco 1 es el líder teniendo un resultado neto del ejercicio positivo y creciente desde el 2017 (s/ 2,988,09), 2018 (s/ 3,341.94) al 2019 (s/ 3,622.71) para el 2020 (s/ 832.89) se redujo en $77 \%$, a pesar de este resultado el banco puede tener liquidez para manejar su flujo de caja y otras operaciones de corto plazo. Otro resultado importante fue de la banca múltiple, aunque se redujo en el 2020 con respecto al 2019 pudo tener un resultado neto de s/ 2,111.57.

\section{Tabla 1}

Evolución de las utilidades de los bancos en el sistema financiero peruano (millones soles)

\begin{tabular}{|c|c|c|c|c|}
\hline Utilidades & 2017 & 2018 & 2019 & 2020 \\
\hline Resultado Neto del Ejercicio "Banco 1" & $2,988.09$ & 3,341.94 & $3,622.71$ & 832.89 \\
\hline Resultado Neto del Ejercicio "Banco 2" & $1,387.09$ & $1,476.02$ & $1,609.90$ & 655.14 \\
\hline Resultado Neto del Ejercicio "Banco 3" & $1,221.02$ & $1,280.65$ & $1,464.74$ & 266.32 \\
\hline Resultado Neto del Ejercicio "Banco 4" & 902.00 & $1,040.06$ & $1,221.52$ & 264.88 \\
\hline Resultado Neto del Ejercicio "Otros bancos" & 728.21 & $1,080.84$ & $1,163.44$ & 92.34 \\
\hline Resultado Neto del Ejercicio "Banca Múltiple" & $7,442.25$ & $8,219.51$ & $9,082.31$ & $2,111.57$ \\
\hline Variación & & 11.84 & 8.40 & $-77 \%$ \\
\hline
\end{tabular}

Fuente: Superintendencia de Banca y Seguros. Elaboración propia 


\section{Marco teórico}

La teoría que sustentan el trabajo de investigación es la política monetaria desarrollada por los economistas como Irving Fisher, Clark Warburton y Milton Friedman quienes manifestaron su importancia en la estabilidad macroeconómica basándose en las ideas de John Stuart Mill sobre la relación que existe entre el nivel general de precios (inflación) con la cantidad de dinero que circula en la economía. Los objetivos son estabilizar el valor del dinero, mantener la tasa de crecimiento económico, impedir los saldos negativos de la balanza de pago, mantener un tipo de cambio adecuado y proteger las reservas internacionales netas. (Banco Central de Reserva del Perú, 2020)

El Banco Central encamina la economía con la finalidad de alcanzar los objetivos económicos mediante la masa monetaria o el coste del dinero basado en la tasa de interés con la finalidad de inyectar liquidez en el sistema financiero, para esto se aplica la política monetaria expansiva para aumentar la cantidad de dinero usando algunos mecanismos, como la reducción de las tasas de interés que incentiva la inversión importante para la generación de la demanda agregada, reducir el encaje bancario que permita a los bancos otorgar más créditos y para generar dinero en el mercado comprando deuda pública la otra política monetaria es la restrictiva cuando hay exceso de dinero en circulación y para reducirlo se incrementa la tasa de interés, haciendo que los prestamos resulten caros, aumentar la tasa de encaje para que haya más dinero en el banco y por último vender la deuda pública. (Marshall y Rochon, 2019).

La nueva teoría cuantitativa permite justificar la demanda del dinero en las transacciones con la finalidad de mantener saldos reales, a través del costo de oportunidad, la asignación de cartera, tipos de interés de otros activos y de la riqueza del individuo, monitoreando el comportamiento de los precios. Esta teoría surge al querer explicar la inflación por la entrada de metales preciosos a Europa como consecuencia de la conquista creando un desequilibrio monetario para dar respuesta a este problema surgen varias posturas entre ellas la de Keynes, quien sustentaba que la demanda de dinero estaría inversa con la tasa de interés siendo esta la que generaría inestabilidad, por otro lado surge la teoría monetarista liderada por Milton Friedman quien considero el corto plazo en las variaciones de la cantidad del dinero incluyendo también la inflación analizando no sólo la cantidad sino el dinero que desean mantener los agentes económicos. Fisher cambiaría la teoría cuantitativa a una demanda de dinero basada en el poder adquisitivo de los medios de pago, servirá para comprar bienes y servicios en función de la oferta y la demanda. (Ussher, Haas, Töpfer, 2018).

El modelo matemático planteado para esta teoría es la siguiente:

$$
M_{t} V_{t}=P_{t} Y_{t}
$$

Donde:

$M_{t}$ : significa la cantidad de dinero en la economía, es decir, la masa monetaria medida como uno de los agregados monetarios.

$V_{t}$ : significa la velocidad que circula el dinero, es decir, es el número de veces que se gasta una unidad monetaria en la compra de bienes y servicios. servicios.

$P_{t}$ : significa el nivel de precios promedio del mercado por el cual se venden los bienes o

Esta obra se comparte bajo la licencia Creative Common Atribución-No Comercial 4.0 International (CC BY-NC 4.0) 
Modelo de recuperación de créditos castigados y la generación de utilidades en el sistema bancario peruano 2017 al 2020

$Y_{t: \text { significa la cantidad real de bienes y servicios producidos, como dato fundamental para }}$ su medición se toma el PBI

Leyendo la ecuación tendríamos, que la cantidad de dinero que circula en la economía se multiplica por el número de veces que se gasta una unidad monetaria esto va a ser equivalente a la producción de un año específico por los precios de mercado (Riera y Blasco Martel, 2016).

A continuación, se detalla algunas definiciones importantes para el desarrollo de la investigación:

Para la SBS (Resolución 11356-2008) se define como Créditos, a los créditos directos y los créditos indirectos, con respecto a los créditos directos, considera al financiamiento otorgado bajo cualquier modalidad por las empresas del sistema financiero a sus clientes y estos devolver en los plazos pactados, los créditos indirectos o llamados créditos contingentes representan los avales, cartas fianzas, aceptaciones bancarias, cartas de créditos, créditos aprobados no desembolsados, las líneas de créditos no utilizadas, otorgados por las empresas del sistema financiero.(Superintendencia de Banca, Seguros y Administradores de fondo de pensiones, 2020)

Deuda morosa (créditos de consumo o hipotecario), se considera a los créditos que registran atrasos hasta 8 días calendario. (Banco de crédito del Perú, 2020)

Deuda vencida (créditos de consumo o hipotecario), cuando tiene atrasos mayores a 30 días se considera vencida las cuotas no pagadas y si el atraso persiste por más de 90 días se considera vencido la totalidad de la deuda. Por lo tanto, podemos decir que se considera deuda vencida, cuando registra un atraso de al menos 30 días en el pago de su deuda. (Maldonado y Guzmán, 2020).

Deuda Castigada, las entidades financieras deben castigar sus créditos clasificados en pérdida siempre que exista evidencia que estos no van a poder ser recuperados o cuando el monto del crédito no justifica iniciar acción judicial o arbitraje, la entidad financiera deberá provisionar el integro de la deuda no cancelada y realizar el reporte ante las centrales de riesgos de la SBS, el cual se mantendrá hasta que la deuda sea transferida, condonada o se supere los motivos que dieron lugar a su castigo. El crédito castigado debe ser retirado del balance de la empresa. (Gómez y Ríos, 2016)

Operaciones Refinanciada; se considera al crédito o financiamiento directo, bajo cualquier modalidad, en la que se producen variaciones en el plazo y/o monto del contrato original debido a dificultades en la capacidad de pago del deudor. (Chu, 2018)

Operaciones reestructuradas; se denominan a los créditos o financiamientos directos bajo cualquier modalidad sujeto a la reprogramación de sus pagos aprobados en el proceso de reestructuración de acuerdo a la Ley General del Sistema Concursal. (Duckardt, López, Albanese y Briozzo, 2019) 
Provisiones; Las empresas deben constituir las provisiones genéricas y específicas sobre los créditos directos y su exposición equivalente a riesgos crediticios de los créditos indirectos. (Ortiz y Celis, 2019).

Provisión Genérica; se constituyen de manera preventiva a los créditos directos y la exposición equivalente a riesgo crediticio de créditos indirectos de deudores clasificados en Normal. (Asociación de Bancos del Perú, 2019)

Provisiones específicas; Se constituyen sobre los créditos directos y la exposición equivalente a riesgo crediticio de créditos indirectos de deudores que se han clasificado en una categoría de mayor riesgo que la normal. (Cofré, Améstica-Rivas, King-Domínguez, RomeroRomero, 2019).

Garantías; Las entidades financieras consideran a las garantías como un colateral que va a respaldar las obligaciones del deudor, pueden ser esta, reales (bienes materiales o activos) o personales (aval y la fianza). (Il Mateus, Ávila y Ortiz, 2016)

Gastos judiciales: Son aquellos gastos en los que se incurren por los pagos realizados a los estudios externos por las gestiones judiciales seguidas contra los deudores. Estos gastos se producen sólo si tiene éxito la cobranza judicial y son pagados con los fondos recuperados o si la deuda es castigada. (Macías, 2020)

\section{Metodología}

La metodología empleada en esta investigación fue de tipo cuantitativa, diseño no experimental y descriptiva, la técnica realizada es el análisis documental y el instrumento la ficha técnica de recolección de datos, los cuales fueron obtenidos de fuentes secundarias de los principales organismos oficiales como, el Banco Central de Reserva del Perú, Superintendencia de Banca y seguros y Administradora de Fondos de pensiones. Para la aplicación del modelo propuesto se tomó los créditos castigados, los cuales siguen un proceso que inicia con la morosidad del cliente (antes de los 15 días), luego continúa a vencido con más de 30 días de vencida la deuda, luego la cartera a medida que se va deteriorando (no se está pagando) se le va clasificando de problemas potenciales a pérdida, paralelamente los créditos vencidos se les inicia un proceso judicial, previa clasificación a pérdida y castigo, si existe garantías el banco procederá al remate. La población son todos los bancos que conforman el sistema financiero peruano, siendo la muestra cuatro principales bancos que tienen una representación significativa en colocación y depósitos.

\section{Resultados}

Para el desarrollo del modelo propuesto se tomó en cuenta la rentabilidad de las propias operaciones de los bancos. Se consideró que la cartera castigada, ya afectó los resultados de ejercicios anteriores y se pretende incrementar los ingresos del banco aportando un mejor sistema 
para la recuperación de esta cartera, en adelante, cuando se mencione "El modelo" se hace referencia a la Cartera Castigada Recuperable.

Con la aplicación e implementación del modelo, se esperó que mejore los resultados económicos de los bancos en los próximos años, para esto deben cumplir los siguientes lineamientos:

- Modificar las normas y procedimientos para la administración de la cartera castigada.

- Apoyar el seguimiento, control y gestión de la administración de cartera castigada

- Implementar un sistema de información de deudas que incluya los movimientos realizados sobre las deudas castigadas.

Para conseguir los objetivos de recuperación en los primeros años, se debe trabajar con aquellas obligaciones que cuenten con garantía real y la coordinación con la unidad legal de los bancos de ser el caso. El tiempo estimado para terminar el Sistema de Información de Deudas, incluyendo las pruebas y carga inicial de información, es de seis meses. Se estima que el modelo se inicie en junio del 2021.

\section{Se consideran como tipos de cobranza:}

- En efectivo

- Bienes muebles e inmuebles: que pueden recibirse como dación en pago o venta a terceros, donde un tercero compra el bien dado en garantía con acuerdo de minuta de levantamiento de garantía condicionada al pago de la deuda y liberación del gravamen.

- Financiamiento propio (refinanciamiento, reestructuración INDECOPI) o financiamiento de terceros.

- Cobranza Judicial: Mediante la ejecución de garantías, embargos, cesión de derechos, entre otros.

\section{Plazo del modelo}

En esta etapa, se evaluó la proyección de los ingresos a tres años, considerando que:

- En ese período de tiempo debe contar con la implementación del nuevo sistema de información.

- Se produjo los cambios administrativos necesarios para su manejo. Se fijó el monto de recuperación de cartera castigada como meta de evaluación individual del desempeño.

- Se terminó con la evaluación total de la cartera y será necesario modificar el nivel de exigencia que inicialmente se fijó para el modelo.

- Estrategias de recuperación: Se dio prioridad a la recuperación de aquellas obligaciones que cuentan con garantía real constituida a favor del banco.

- El apoyo legal se consideró como factor clave de éxito para el logro de esta gestión.

- Requerimientos de inversión: La inversión en hardware, licencias, personal encargado del desarrollo del software del proyecto y otros se ha estimado en $\$ 72,571$ 
- Gastos del proyecto: De acuerdo con la información del área de Auditoría Interna del banco los casos en legal representan el $85 \%$ del total de la cartera castigada recuperable.

\section{Gestión de recuperaciones y evaluación económica del modelo}

Para gestionar la recuperación de la cartera castigada se sugiere implementar el modelo al que se denominó, sistema de recuperación de créditos castigados.

Se planteó lo siguiente: Primero, identificar la cartera castigada recuperable, segundo, mejorar la gestión del funcionario de recuperaciones fijando metas de recuperación tomando en cuenta la cartera castigada recuperable y tercero seguimiento de la gestión de la cartera castigada recuperable.

\section{Tabla 2}

Evolución de la cartera atrasada y castigada del 20|17 al 2020 al 31 de diciembre (millones soles)

\begin{tabular}{ccrrrrrrr}
\hline \multirow{2}{*}{ Años } & \multirow{2}{*}{$\begin{array}{c}\text { Colocaciones } \\
\text { Netas }\end{array}$} & \multirow{2}{*}{ Refinanciados } & \multicolumn{2}{c}{ Atrasados } & \multicolumn{2}{c}{ Castigos } & Provisiones \\
\cline { 4 - 8 } & & & Vencidos & Judicial & Sub total Atrasados & \\
\hline 2017 & $233,101.09$ & $3,318.51$ & $3,516.81$ & $3,948.81$ & $7,465.62$ & 369.23 & $-11,361.08$ \\
2018 & $257,825.11$ & $4,035.04$ & $3,419.55$ & $4,567.13$ & $7,986.67$ & 446.29 & $-12,235.87$ \\
2019 & $272,524.28$ & $4,112.55$ & $4,145.61$ & $4,491.41$ & $8,637.02$ & 456.06 & $-13,111.21$ \\
2020 & $307,086.94$ & $5,612.84$ & $7,224.49$ & $5,162.22$ & $12,386.71$ & 755.98 & $-21,967.76$ \\
\hline
\end{tabular}

Fuente: SBS Información de la Banca múltiple

Como se observa en la tabla 2 las colocaciones netas (créditos directos) han venido incrementándose cada año, notándose un mayor crecimiento en el 2020, esto se debe a la inyección de liquidez por parte del gobierno para tratar de paliar la situación financiera de los principales sectores de la economía que fueron afectados por la pandemia, del mismo modo a mayor crecimiento de las colocaciones mayor es el incremento de los créditos atrasados y por ende mayor castigo, como se aprecia al detalle en el 2020.

Con respecto a la deuda atrasada y castigada en el 2020 que ascienden a 12, 386.71 y 755.98 millones de soles respectivamente, las instituciones financieras peruanas tendrán una ardua tarea para gestionar la recuperación de sus créditos, dado que se ha visto la necesidad de ofrecer una alternativa para revertir esta situación, como se muestra en la figura 5: 


\section{Figura 5}

Modelo - Recuperación de cartera castigada

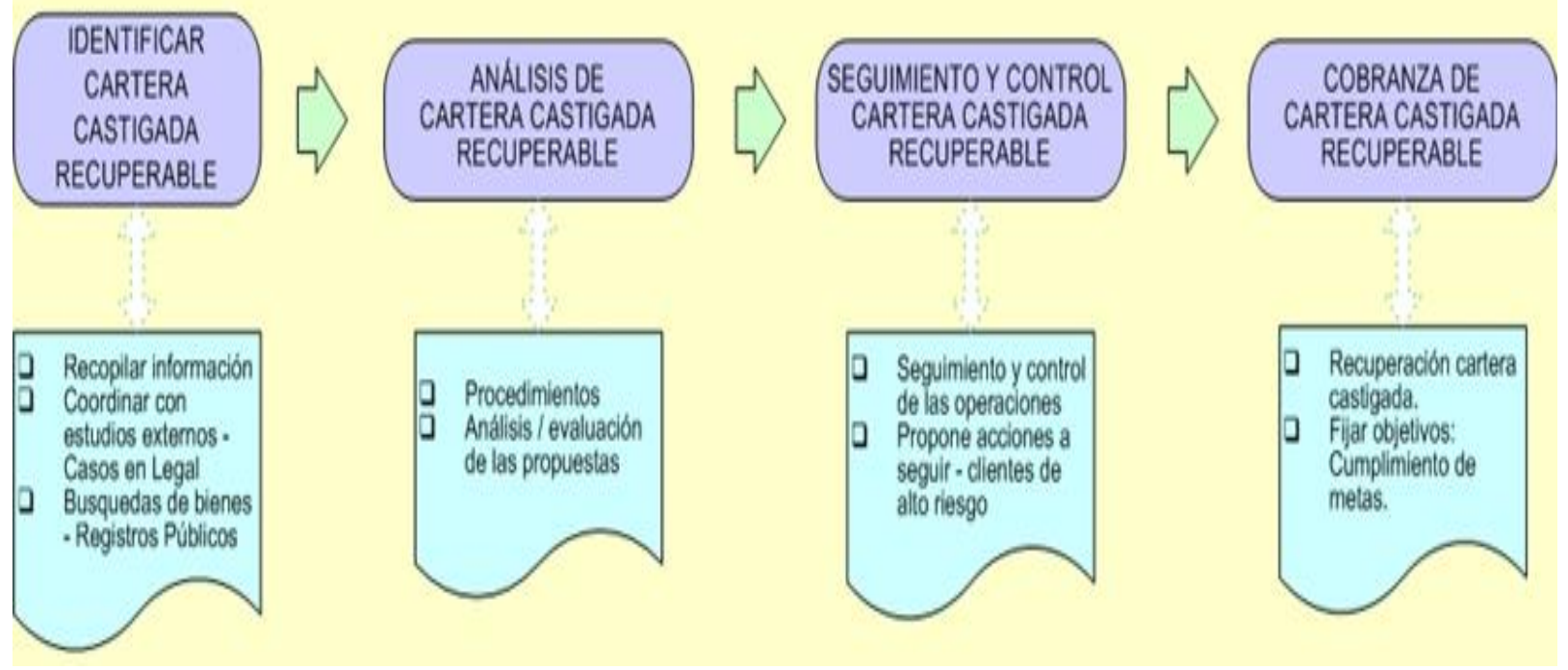

Fuente: Elaboración propia

Podemos mencionar algunas ventajas del modelo propuesto para la recuperación de la cartera castigada:

El área de recuperaciones podrá realizar un mejor análisis de la cartera castigada recuperable, separando de la no recuperable para así aplicar eficientes estrategias de cobranza en forma rápida y oportuna, teniendo como funciones de ser responsables de definir el proceso de administración de cartera castigada, desarrollar herramientas de planeamiento y apoyo, establecer metodologías que prioricen procesos de recuperación de la cartera castigada y tener como apoyo al área legal.

Estimar la probabilidad del tiempo de cobranza y desarrollar un programa que permita a los bancos actualizar en tiempo real los movimientos realizados sobre créditos otorgados. Este programa se va a convertir en un factor clave para el éxito de la gestión de los funcionarios de recuperaciones. El área de seguimiento emitirá reportes para controlar la evolución de la gestión realizada sobre la cartera castigada de tal modo mantener a la gerencia informada para la toma de decisiones, las funciones deberán ser de establecer alarmas para el seguimiento de los créditos castigados, informar de manera periódica la evolución de los créditos y apoyar en el control de garantías.

Visión conceptual del modelo de recuperación de cartera castigada: En el análisis de factores micro (cualitativo y cuantitativo) se utilizarán aquellos criterios relevantes y que se vinculan directamente con este tipo de cartera. Se precisa que si el cliente solicita financiar una deuda castigada, que requiera el desembolso de un nuevo crédito, se aplicará el modelo original del Área de Recuperaciones (Cofré, Améstica, King y Romero, 2019) 


\section{Figura 6}

\section{Visión Conceptual del modelo de recuperación (Variables)}
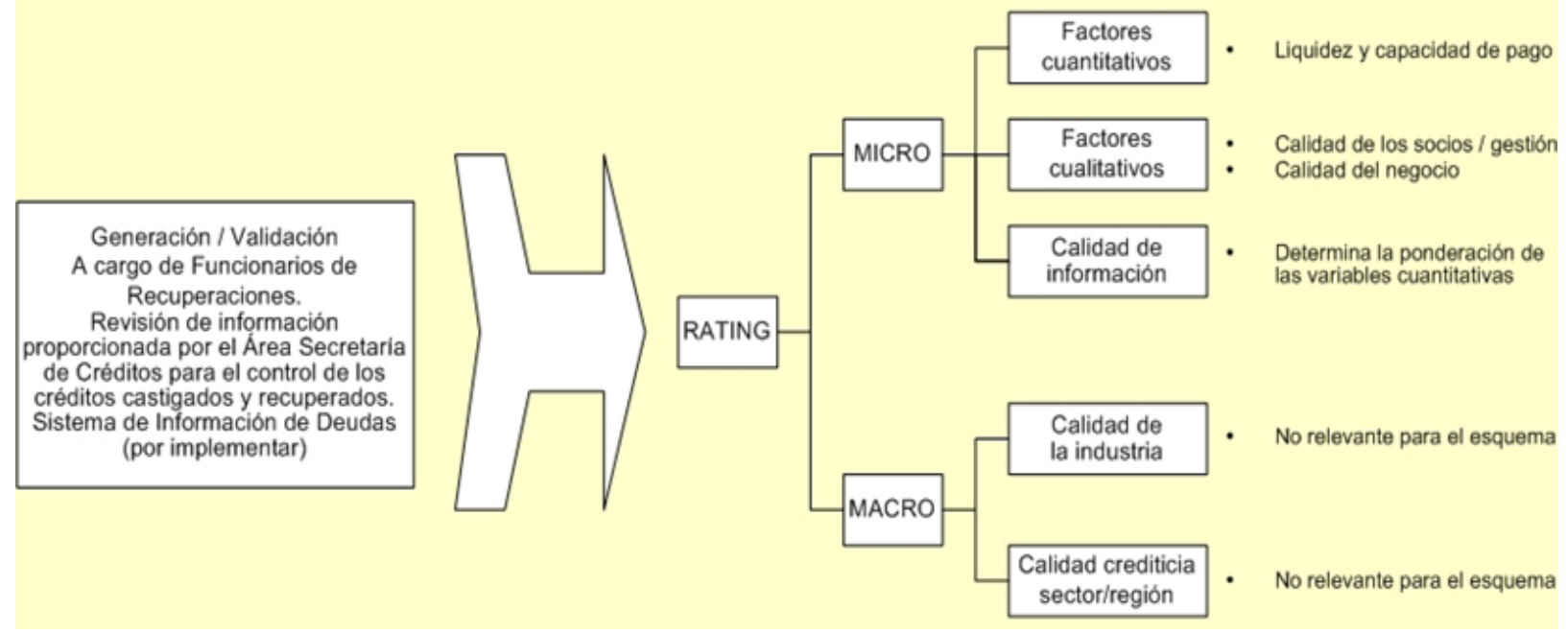

Fuente: Elaboración propia

En el modelo Recuperación de Cartera Castigada, el factor cuantitativo liquidez es el único considerado atendiendo a que la deuda está castigada y no cambiará de situación contable, los pagos realizados afectarán directamente a los resultados del banco, otros factores cuantitativos no son relevantes para la recuperación del crédito castigado. Por otro lado, los factores cualitativos: calidad de las personas / socios / gestión, complementarán la evaluación y apoyarán la decisión.

\section{Figura 7}

Factores macro - micro del modelo

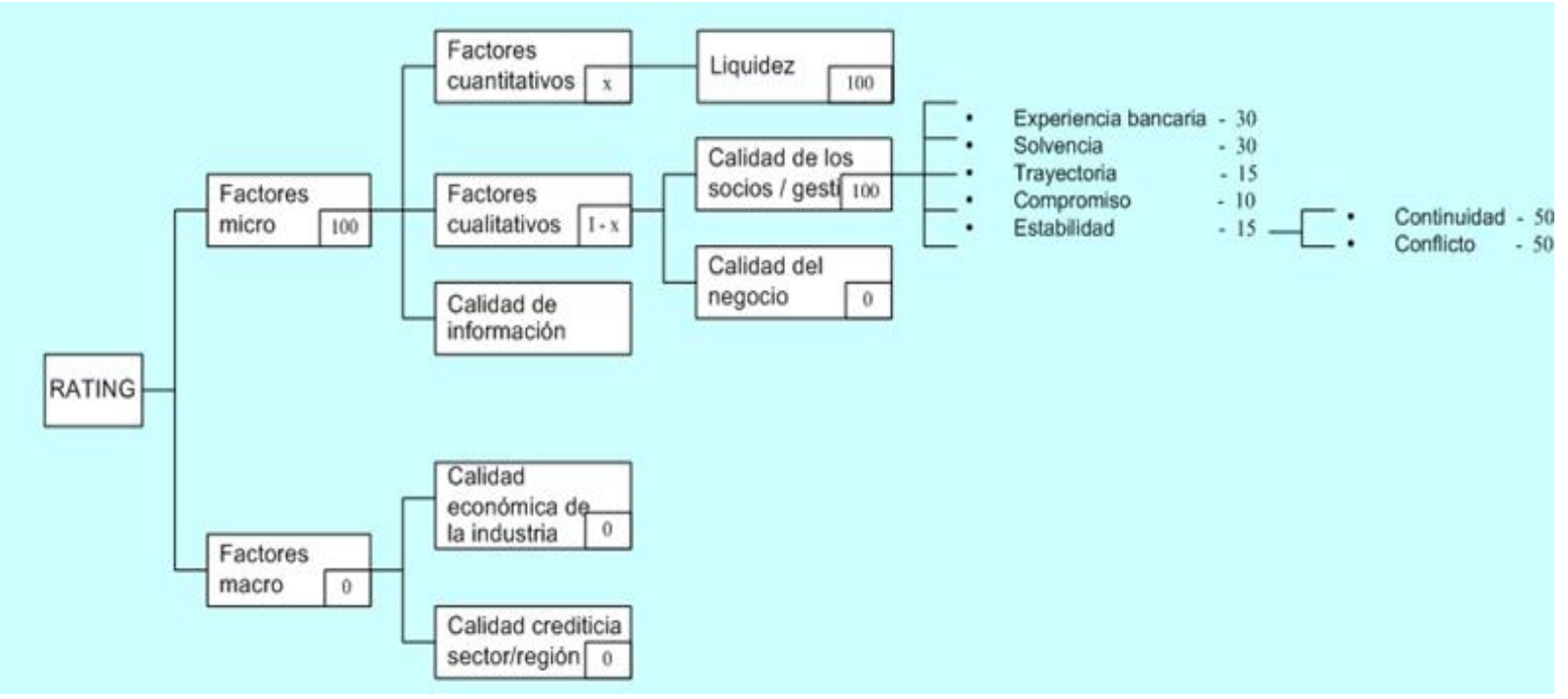

Fuente: Elaboración propia 
La particularidad de este modelo es que no se asume mayor riesgo, el crédito ya se encuentra castigado y cualquier pago contribuirá con los ingresos del banco. La implicancia sería la ponderación asignada al factor cuantitativo liquidez, está relacionada con el efecto de la recuperación en los resultados de los bancos. Esta idea se expresa en la figura 8:

\section{Figura 8}

Proceso básico: apoyo del sistema de recuperación de créditos Castigados

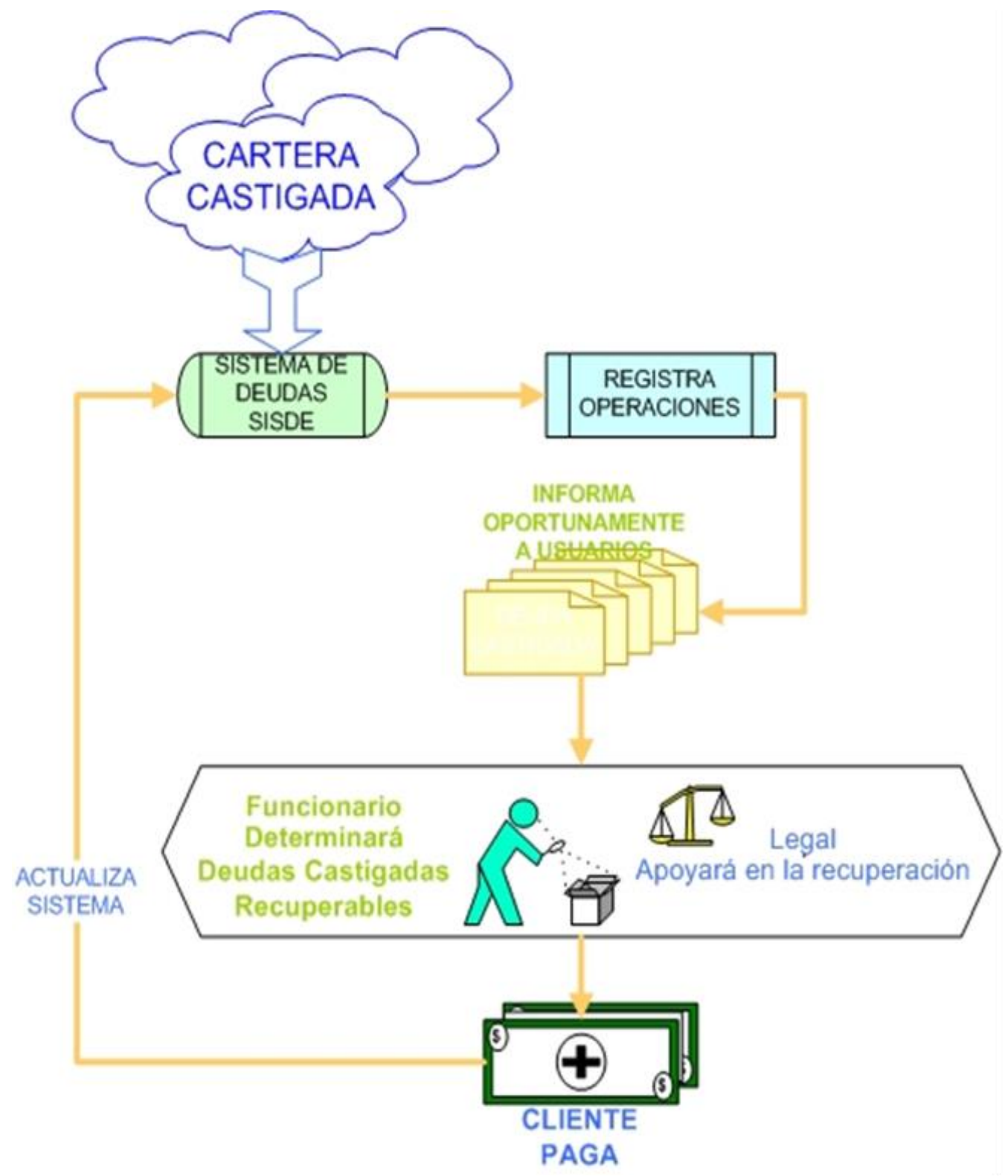

Fuente: Banco de crédito del Perú. Elaboración propia. 


\section{Costo del Sistema de Información de Deudas (SISDE):}

Los bancos cuentan con parte de la infraestructura (espacio físico que puede designar) y equipos de cómputo que puede utilizar (a tarifas muy convenientes).

Con la finalidad de establecer el costo / inversión inicial del modelo se toma en cuenta los siguientes supuestos:

- El personal que desarrolló el proyecto fue un proveedor (empresa de sistemas de terceros).

- El hardware que se utilice fue nuevo y exclusivo para el modelo.

- El software que se utilice y sus respectivas licencias se ha cotizado a valor de mercado.

- El desarrollo del proyecto (levantamiento de información, desarrollo, pruebas, implementación y pase a producción) se ha estimado en 6 meses.

- El tipo de cambio a utilizar es el de oferta demanda (S/ 3.71 por dólar).

En otros costos, se incluye lo siguiente:

- Espacio físico (incluye energía eléctrica, mantenimiento, entre otros) calculado de manera proporcional al área utilizada y de acuerdo con la distribución por centro de costos del banco.

- El espacio físico de $30 \mathrm{~m} 2$, cuyo precio por alquiler se ha fijado en $\$ 550$ mensuales, equivale a $\$ 3,300$.

- Muebles: adquisición del mobiliario necesario para el mejor desarrollo del modelo (escritorios, sillas, armarios, entre otros) por un valor de $\$ 2,200$

- Útiles de oficina: se incluye lapiceros, lápices, borradores, resaltadores, papel, sellos, tampón, tinta, tóner, entre otros, $\$ 3,000$ por todo el proyecto.

- Medios magnéticos de soporte: memorias USB, disco duro externo entre otros \$2,200 para la aplicación del modelo.

La capacitación del personal del banco se efectuó bajo las siguientes premisas:

\section{Tabla 3}

Supuestos de capacitación del personal (Tipo de cambio s/3.71)

\begin{tabular}{|c|c|c|c|c|c|c|c|c|}
\hline & Cantidad & $\begin{array}{l}\text { Sueldo } \\
\text { mensual } \\
\text { promedio } \\
\end{array}$ & $\begin{array}{l}\text { Sobre } \\
\text { Costo } \\
\end{array}$ & Total & $\begin{array}{l}\text { Horas } \\
\text { efectiva } \\
\text { s al mes } \\
\end{array}$ & $\begin{array}{l}\text { Sueldo } \\
\text { hora }\end{array}$ & $\begin{array}{l}\text { Horas } \\
\text { capac. }\end{array}$ & $\begin{array}{l}\text { Costo total } \\
\text { capacitació } \\
\text { n }\end{array}$ \\
\hline $\begin{array}{l}\text { Jefes de Equipo } \\
\text { Funcionarios de }\end{array}$ & 4 & $4,464.29$ & 401.79 & $4,866.07$ & 144 & 33.93 & 20.00 & $2,703.00$ \\
\hline Recuperaciones & 29 & $1,636.90$ & 147.32 & $1,784.23$ & 144 & 12.50 & 20.00 & $7,186.00$ \\
\hline Asistente de Recuperaciones & 8 & $1,190.48$ & 107.14 & $1,297.62$ & 144 & 8.93 & 20.00 & $1,442.00$ \\
\hline Funcionarios de Seguimiento & 15 & $1,488.10$ & 133.93 & $1,622.02$ & 144 & 11.31 & 28.00 & $4,731.00$ \\
\hline
\end{tabular}

Fuente: Elaboración propia 


\section{Inversión Inicial consolidado:}

Para conocer el detalle de cada rubro ver se puede observar la tabla 4 donde se detalla el costo/ inversión consolidada.

\section{Tabla 4}

\section{Costo/inversión}

\begin{tabular}{ll}
\hline \multicolumn{1}{c}{ Costo / Inversión } & Importe $\$$ \\
\hline Servicios de terceros & $\$ 24,300$ \\
Hardware & $\$ 13,700$ \\
Software & $\$ 7,808$ \\
Otros gastos & $\$ 10,700$ \\
Capacitación de personal del banco & $\$ 16,172$ \\
\multicolumn{1}{r}{ Total Costo / Inversión } & $\$ 72,680$ \\
\hline
\end{tabular}

\section{Fuente: BCP-Elaboración propia}

La escala por honorarios que le corresponde al estudio externo está vinculada al monto de la recuperación de la deuda y es la siguiente:

\section{Tabla 5}

Honorarios de estudios externos

\begin{tabular}{lc}
\hline Recuperación de deuda & Honorario(\%) \\
\hline Hasta US $\$ 5,000$ & $15 \%$ \\
Más de US $\$ 5,000$ hasta US $\$ 20,000$ & $10 \%$ \\
Más de US $\$ 20,000$ & $5 \%$ \\
\hline
\end{tabular}

Fuente: BCP - elaboración propia

Gastos prejudiciales y gastos y costas judiciales: Se asume un incremento del 3\% anual atendiendo a la variación de la Unidad de Referencia Procesal (URP) que es el 10\% de la Unidad Impositiva Tributaria (UIT). Con base en la información anterior se ha estimado los gastos unitarios por cada caso y se muestran en la siguiente tabla:

\section{Tabla 6}

Gastos de cobranza judicial (millones soles)

\begin{tabular}{lrrr}
\hline Conceptos & Año 1 & Año 2 & Año 3 \\
\hline Arancel judicial & 100 & 103 & 106 \\
Arancel para remate & 320 & 330 & 339
\end{tabular}




\begin{tabular}{lrrr}
\hline \multicolumn{1}{c}{ Conceptos } & Año 1 & Año 2 & Año 3 \\
\hline Avisos-publicación & 1,000 & 1,030 & 1,061 \\
Cédulas de notificación (4) & 200 & 206 & 212 \\
Copias de documentos & 100 & 103 & 106 \\
Ficha registral & 150 & 155 & 159 \\
Gastos notariales & 100 & 103 & 106 \\
Gastos prejudiciales & 2,000 & 2,060 & 2,122 \\
Movilidad & 200 & 206 & 212 \\
Otros gastos & 1,200 & 1,236 & 1,273 \\
Procuración & 200 & 206 & 212 \\
Reportes & 20 & 21 & 21 \\
Total en s/. & $\mathbf{5 , 5 9 0}$ & $\mathbf{5 , 7 5 9}$ & $\mathbf{5 , 9 2 9}$ \\
\hline
\end{tabular}

Fuente: BCP-elaboración propia

\section{Gastos de personal}

Se remunerará al personal con un bono de éxito equivalente al $1.5 \%$ de la cobranza esperada condicionado al logro. Este fondo se distribuirá entre todo el personal involucrado en la gestión de recuperación de acuerdo con las políticas establecidas por el Área de Recuperaciones.

\section{Supuesto de recupero de la cartera en un escenario actual:}

La recuperación de la cartera castigada según banco líder recupera aproximadamente el $8.39 \%$ de los créditos castigados y se aprecia que la recuperación es decreciente, sin realizar ninguna gestión de cobranza, cabe indicar que en este escenario no se implementa el proyecto y se continúa con la recuperación de la cartera castigada por la inercia del sistema, por ejemplo de clientes que se encuentran en archivo negativo del banco y desean reinsertarse en el sistema financiero, por lo que se acercan al banco a pagar sus deuda, también un $40 \%$ de la cartera castigada se estima que es recuperable, como se muestra en la tabla 7:

\section{Tabla 7}

Supuesto de recupero

\begin{tabular}{ccccc}
\hline Año & $\begin{array}{c}\text { Cartera } \\
\text { castigada }\end{array}$ & $\begin{array}{c}\text { Cartera recuperable } \\
\text { estimada total }\end{array}$ & Recuperación castigo & Tendencia \\
\hline $\mathbf{2 0 1 7}$ & 113.93 & 45.57 & 9.56 & $8.39 \%$ \\
$\mathbf{2 0 1 8}$ & 132.31 & 52.93 & 11.10 & $8.39 \%$ \\
$\mathbf{2 0 1 9}$ & 137.62 & 55.05 & 11.55 & $8.39 \%$ \\
$\mathbf{2 0 2 0}$ & 208.78 & 83.51 & 17.52 & $8.39 \%$ \\
$\mathbf{2 0 2 1 *}$ & 191.26 & 76.50 & 16.05 & $8.39 \%$ \\
$\mathbf{2 0 2 2}^{*}$ & 175.21 & 70.09 & 14.70 & $8.39 \%$ \\
$\mathbf{2 0 2 3}^{*}$ & 160.51 & 64.21 & 13.47 & $8.39 \%$ \\
\hline
\end{tabular}

*Información estimada. Al saldo de la deuda de cartera castigada de cada año se le dísminuye el importe de la cobranza del año anterior.

Fuente: BCP-Elaboración propia 


\section{Supuesto de ingresos en el escenario del modelo propuesto:}

Para la implementación del modelo se consideró la recuperación castigada a un $10 \%$ de la cartera recuperable estimada, es una meta ambiciosa, pese a las circunstancias de la pandemia, dado que se tomó estrategias coordinadas con el área legal, soporte muy importante en la gestión de recuperación para este tipo de créditos. En el análisis de sensibilidad practicado, se debe lograr un $19.2 \%$ (2021), 17.09\% (2022) y 15.04\% (2023) más de la recuperación anual estimada con respecto al escenario actual. Este monto es considerable aceptable porque cumple con el requerimiento de superar el 10\% de la recuperación de cartera castigada

\section{Tabla 8}

Supuesto de ingresos

\begin{tabular}{ccccc}
\hline Año & $\begin{array}{c}\text { Cartera } \\
\text { castigada }\end{array}$ & $\begin{array}{c}\text { Cartera recuperable } \\
\text { estimada total }\end{array}$ & Recuperación castigo & Tendencia \\
\hline $\mathbf{2 0 1 7}$ & 113.93 & 45.57 & 9.56 & $8.39 \%$ \\
$\mathbf{2 0 1 8}$ & 132.31 & 52.93 & 11.10 & $8.39 \%$ \\
$\mathbf{2 0 1 9}$ & 137.62 & 55.05 & 11.55 & $8.39 \%$ \\
$\mathbf{2 0 2 0}$ & 208.78 & 83.51 & 17.52 & $8.39 \%$ \\
$\mathbf{2 0 2 1}^{*}$ & 191.26 & 76.50 & 19.13 & $10.00 \%$ \\
$\mathbf{2 0 2 2}^{2023}$ & 172.13 & 68.85 & 17.21 & $10.00 \%$ \\
\hline
\end{tabular}

*Información estimada. Al saldo de la deuda de cartera castigada de cada año se le disminuye el importe

De la cobranza del año anterior.

Fuente: bcp-elaboración propia

\section{Impuesto a la renta:}

De acuerdo al texto del artículo 1o de la ley No 30296 se determinó modificación a la norma de manera escalonada que hasta el 2014 era del 30\% y continuar hasta llegar al año 2019 en adelante con el $26 \%$, ver tabla 9:

\section{Tabla 9}

Ley de impuesto a la renta $N^{\circ} 30296$

\begin{tabular}{cc}
\hline Ejercicios Gravables & Tasa \\
\hline $2015-2016$ & $28 \%$ \\
$2017-2019$ & $27 \%$ \\
2019 en adelante & $26 \%$ \\
\hline
\end{tabular}

Fuente: Actualidad Empresarial N`317-2014 


\section{Costo de oportunidad de capital (cok)}

El COK va a permitir efectuar las estimaciones económicas del proyecto, se considera el rendimiento sobre el capital contable común o ROE de la banca múltiple calculado para el 2019: $17.25 \%$ dado que el ROE del 2020 no es representativo como sabemos por problemas de la pandemia COVID 19 la economía peruana y mundial han tenido problemas financieros. Ver tabla 10 .

\section{Tabla 10}

Costo de oportunidad de capital

\begin{tabular}{cc}
\hline AÑ & ROE \\
\hline 2020 & $3.93 \%$ \\
2019 & $17.25 \%$ \\
2018 & $17.31 \%$ \\
2017 & $17.05 \%$ \\
\hline
\end{tabular}

Fuente: Bca.Multiple/ elaboración propia

Para la aplicación del modelo propuesto es muy importante la evaluación de los flujos de caja económico y se ha considerado los siguientes escenarios:

\section{Escenario Actual:}

Según los supuestos formulados, cuando la cartera castigada no se gestiona, el resultado que se obtuvo es de un valor actual neto (VANE) equivalente a \$23.24 millones de dólares ver tabla 11 .

\section{Tabla 11}

Flujo de caja económico-actual (millones de soles)

\begin{tabular}{|c|c|c|c|c|}
\hline Período & Año 0 & Año 1 & Año 2 & Año 3 \\
\hline Ingresos & & 16.05 & 14.70 & 13.47 \\
\hline Egresos & 0 & 4.63 & 4.27 & 3.94 \\
\hline \multicolumn{5}{|l|}{ Costo de inversión } \\
\hline Honorario estudios jurídicos & & 0.23 & 0.23 & 0.22 \\
\hline Gastos y costas judiciales & & 0.16 & 0.15 & 0.15 \\
\hline Gastos de personal & & 0.07 & 0.07 & 0.06 \\
\hline Impuestos & & 4.17 & 3.82 & 3.50 \\
\hline Flujo de caja económico & 0 & 11.42 & 10.43 & 9.53 \\
\hline Costo de oportunidad de capital & $17.25 \%$ & & & \\
\hline Valor presente neto & 23.24 & & & \\
\hline
\end{tabular}




\section{Escenario estimado:}

Al realizar las estimaciones en este escenario, El modelo original desarrollado por la consultora internacional McKinsey para la creación del área Recuperaciones tuvo un costo para el banco la cantidad de $\$ 5.5$ millones de dólares, según informaciones sobre la evolución de la cartera de recuperaciones del 2012 a diciembre del 2016 , se estima que el referido modelo original no cumplió con su objetivo de cobrar el $100 \%$ de la deuda, por lo que el banco tuvo que castigar en promedio un $26.6 \%$, el importe que le corresponde asignar como inversión inicial al modelo propuesto, será el $26.6 \%$ de la inversión original de $\$ 5.5$ millones de dólares, que equivale a $\$ 1.463$ millones de dólares, a ello sumamos los $\$ 72,680$ de costos se obtiene un monto total de inversión de \$1.54 millones de dólares, por lo que se obtendrá un VANE equivalente a \$25.93 millones de dólares con este resultado se puede aceptar el modelo, ver tabla 12.

\section{Tabla 12}

Flujo de caja económico - estimado (millones de dólares)

\begin{tabular}{|c|c|c|c|c|}
\hline Período & Año 0 & Año 1 & Año 2 & Año 3 \\
\hline Ingresos & & 19.13 & 17.21 & 15.49 \\
\hline Egresos & 1.54 & 5.43 & 4.92 & 4.46 \\
\hline \multicolumn{5}{|l|}{ Costo de inversión } \\
\hline Honorario estudios jurídicos & & 0.23 & 0.23 & 0.22 \\
\hline Gastos y costas judiciales & & 0.16 & 0.15 & 0.15 \\
\hline Gastos de personal & & 0.07 & 0.07 & 0.06 \\
\hline Impuestos & & 4.97 & 4.48 & 4.03 \\
\hline Flujo de caja económico & -1.54 & 13.70 & 12.29 & 11.03 \\
\hline Costo de oportunidad de capital & $17.25 \%$ & & & \\
\hline
\end{tabular}

\section{Flujo de caja incremental}

Realizados los cálculos en base a los supuestos formulados anteriormente se determina un VANE incremental de \$2.69 millones de dólares y una TIRE de 121\%, con estos resultados se acepta el modelo propuesto.

\section{Tabla 13}

Valor neto incremental (millones de dólares)

\begin{tabular}{ccccc}
\hline Período & Año 0 & Año 1 & Año 2 & Año 3 \\
\hline Flujo de caja económico incremental & -1.54 & 2.28 & 1.86 & 1.50 \\
Costo de oportunidad de capital & $17.25 \%$ & &
\end{tabular}




\begin{tabular}{|c|c|c|c|c|}
\hline Período & Año 0 & Año 1 & Año 2 & Año 3 \\
\hline Tasa interna de retorno & $121.00 \%$ & & & \\
\hline Valor presente neto incremental & 2.69 & & & \\
\hline
\end{tabular}

\section{Análisis de sensibilidad}

De acuerdo con el análisis de sensibilidad se deduce que el incremento de la recuperación de la cartera castigada luego de la aplicación del proyecto debe ser superior a $17.25 \%$, obteniendo una Tasa Interna de Retorno del $121.00 \%$ valor con el cual el VANE es igual a cero.

\section{Conclusiones}

A raíz de la pandemia del COVID 19 ha traído crisis económica y por ende los índices de morosidad y de cartera vencida se han incrementado, del mismo modo los bancos a raíz de todo ellos se han visto obligados a castigar los créditos vencidos y por lo tanto van a tener que redefinir su modelo operativo de cobranza, como se ha visto que, en el año 2020 la banca múltiple ha tenido que castigar créditos por 755.98 millones de soles, es decir, un 66\% más con respecto al año anterior. Muy a pesar de lo sucedido con los créditos las utilidades del sistema bancario en el 2020 han sido positivas llegando a tener utilidades la banca múltiple por 2,111.57 millones de soles pero disminuida en un $77 \%$ con respecto al año anterior 2019 que obtuvo su cifra récord de 9,082.31 millones de soles.

Es necesario entender que la gestión eficiente de una cobranza debe dar inicio con una rigurosa calificación al momento de desembolsar los créditos, una deficiente calificación de los créditos, ya sea en la etapa de recolección de datos, administración del riesgo o mediante la asignación de las líneas de créditos, va a generar problemas en la gestión de cobranza, por ello los sistemas de calificación de crédito que utilizan las instituciones bancarias resultan muy exigentes, esta situación se refleja en la tendencia creciente que se registra en el indicador colocaciones.

Para los años 2018, 2019 y 2020 la cartera refinanciada ha tenido un incremento de $22 \%$, $2 \%$ y $36 \%$ con respecto al año anterior respectivamente y la cartera atrasada (vencida más la judicializada) ha tenido un incremento de $7 \%, 8 \%$ y $43 \%$ con respecto al año anterior respectivamente. Es preciso resaltar que el año 2020 ha sido bastante atípico por los resultados de los porcentajes mostrados. Por los que los bancos deberán controlar los elevados indicadores de morosidad, sobre todo en los sectores de mediana empresa, pequeña empresa, microempresa y sobre todo mayor control en la banca de consumo.

Recalcar la importancia de los indicadores de cartera atrasada de la banca múltiple registran niveles promedio del mercado nacional e internacional en los años anteriores incluso en el 2019. En el escenario propuesto, el modelo resulta favorable para las instituciones bancarias dado que arroja un VAN de $\$ 25.93$ millones de dólares con un COK (ROE) del 17.25\%, con respecto al flujo de caja incremental arroja un Valor Neto Presente Incremental de \$2.69 millones de dólares y una TIR del 121\%. Durante el periodo de crisis económica que viene afectando al país producto de la pandemia COVID 19, el modelo propuesto ayudará a las instituciones bancarias a mejorar la eficiencia de la cobranza, sobre todo deberá enfocarse en brindar un mejor servicio al cliente, las 
Modelo de recuperación de créditos castigados y la generación de utilidades en el sistema bancario peruano 2017 al 2020

instituciones deben ser flexibles al cambio para proteger o incrementar la utilidad o reducir pérdidas, mientras se gestionen nuevos productos y estrategias para los segmentos de clientes que se encuentren en riesgo o que tengan cartera vencida o castigada.

\section{Referencias bibliográficas}

ASBANC- Asociación de Bancos del Perú (2019), Boletín bancario. http://www.asbanc.com.pe Banco Central de Reserva del Perú (2020). Notas semanales. http://www.bcr.org.pe Banco de Crédito del Perú. (2016). Memoria Anual 2016. Lima, Perú

Barcelos Silva, E., Couto Fernandes, V. D., Vázquez Carrazana, X. E., y José Miranda, G. (2020). Análise Comparativa dos Indicadores Econômico-Financeiros entre Bancos do Brasile dos Estados Unidos. Gestión Joven, 21(3), 16-34.

BCP-Banco de Crédito del Perú, Boletines mensuales. http://www.viabcp.com.pe

Cante, F. (2020). la política económica como catalizador de las crisis. análisis político, 33(100), 55-71. $\quad \underline{\text { https://search.proquest.com/scholarly-journals/la-política-económica-como- }}$ catalizador-de-las/docview/2499098678/se-2?accountid=37408

Cofré Sepúlveda, L., Améstica-Rivas, L., King-Domínguez, A., y Romero-Romero, R. (2019). Eficiencia del sector bancario en Chile ante cambios en las regulaciones de protección al consumidor financiero*. Cuadernos de Contabilidad, 20(50), 1-21. https://doi.org/10.11144/Javeriana.cc20-50.esbc

Chu, R. M. (2018). Fundamentos de Finanzas, Un Enfoque Peruano. (9 ${ }^{\text {ma }}$ edición). Lima, Perú: Colegio de Economistas

Cruz-García, P., De Guevara, J. F., y Maudos, J. (2018). Bajos tipos de interés en la eurozona: impacto sobre los márgenes y la rentabilidad de los bancos. Papeles de economía española, (155), 132-146. https://search.proquest.com/scholarly-journals/bajos-tipos-de-interés-en-laeurozona-impacto/docview/2033731024/se-2?accountid $=37408$

Duckardt, B., López, M. de los Á., Albanese, D., y Briozzo, A. (2019). La importancia del informe de auditoría para el otorgamiento de crédito*. Cuadernos de Contabilidad, 20(50), 1-22. https://doi.org/10.11144/Javeriana.cc20-50.iiao

G., D. P., Maldonado, J. M., y Guzmán, M. D. (2020). Perspectivas económico-financieras de la banca pública frente al impacto del COVID-19. Journal of Alternative Perspectives in the Social Sciences, 10(4), 1197-1205.

Gómez Daza, J. A., y Ríos Saavedra, O. A. (2016). Impacto de la gestión de riesgos sobre la eficiencia bancaria en costos, un caso aplicado a los bancos en Colombia. Cuadernos de Administración, 32(56), 36-49

il Mateus, E. O., Ávila Perico, H. D. y Ortiz Villalobos, A. E. (2016). Mercados financieros, eficiencia y adaptación. Equidad \& Desarrollo (26), 191-206. http://doi.org/10.19052/ed.3735

María Teresa Macías. (2020). Guía del gerente financiero. Desde el diagnostico hasta la toma de decisiones. Universidad de La Sabana.

MarketLine Company Profile: Banco de Credito del Peru SA. (2020). Banco de Crédito Del Perú MarketLine Company Profile, 1-20.

Marshall, W. C., \& Rochon, L.-P. (2019). Public Banking and Post-Keynesian Economic Theory. International Journal of Political Economy, 48(1), 60-75. https://doi.org/10.1080/08911916.2018.1550947 
Ortiz Bojacá, J. J., y Celis, H. (2019). Las Finanzas Conductuales y La Teoría Del Riesgo: ¿Nuevos Fundamentos Para La Gerencia Financiera?. Revista Criterio Libre, 18(31), 4582. https://doi.org/10.18041/1900-0642/criteriolibre.2019v18n31.6130

Riera, C y Blasco- Martel, Y (2016). Teoría cuantitativa del dinero. La Demanda de dinero en España: 1883 - 1998. Madrid. Banco de España

Superintendencia de Banca, Seguros y Administradores de fondo de pensiones (2020). Boletín mensual. http://www.sbs.gob.pe

Ussher, L. J., Haas, A., Töpfer, K., \& Jaeger, C. C. (2018). Keynes and the international monetary system: Time for a tabular standard? European Journal of the History of Economic Thought, 25(1), 1-35. https://doi.org/10.1080/09672567.2017.1365093

Wray, L. R. (2020). Caminos alternativos a la teoría monetaria moderna. Revista De Economía Institucional, 22(43), 29-56. http://doi.org/10.18601/01245996.v22n43.03 